\title{
Diálogos possíveis: uma leitura benjaminiana de $A$ Corte do Norte, de Agustina Bessa-Luís
}

Isadora Almeida Rodrigues Universidade Federal de Minas Gerais

\section{Agustina, pensadora}

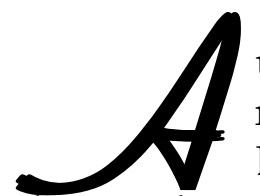
utora de mais de 60 livros entre romances, contos, novelas e crônicas, a escritora portuguesa Agustina Bessa-Luís é mais do que uma autora de ficção. Ao longo de sua obra é possível notar a construção de um pensamento próprio, de uma visão bastante peculiar do mundo, da sociedade e, principalmente, das relações familiares. Em meio aos enredos, aos personagens, à ficção, seus livros vão apresentando uma concepção única de mundo, de família e de sociedade, num pensamento cáustico e imprevisível. Agustina subverte as concepções tradicionais de casamento, de maternidade, de amor, do que é ser mulher na sociedade contemporânea, e faz ainda importantes considerações sobre psicanálise, política, história e filosofia.

O tom filosófico da poética de Agustina fica ainda mais evidente em $A$ Corte do Norte, romance de 1986 a ser trabalhado neste texto. Nele, o pensamento da escritora é colocado de forma a quase se sobressair ao enredo. Em meio à história do enigma do desaparecimento de Rosalina, a Baronesa de Madalena do Mar, a autora dispõe ao leitor um sem número de análises, digressões, concepções de mundo que, tão 
recorrentes, fazem deste romance uma espécie de enciclopédia de seu pensamento.

Em muitos de seus romances, Agustina utiliza-se do recurso da digressão do narrador para "salpicar" ideias, conceitos e concepções bastante únicos, como já afirmado. Em $A$ Corte do Norte, entretanto, o pensamento de Agustina se constrói não só nessas digressões, mas também na forma como se estrutura o enredo e no diálogo explícito e implícito com grandes pensadores modernos. Os nomes de Nietzsche, Freud, Fernando Pessoa, Walter Benjamin, entre outros, são citados de forma direta e indireta - alguns bastante recorrentes - ao longo do romance, de forma a fazer com que o pensamento da autora se integre, dialogue, se aproxime e se afaste das concepções construídas na modernidade.

Embora sejam muitas as possibilidades de reflexão proporcionadas por este romance, neste trabalho, privilegiarse-ão os diálogos de Agustina com o pensamento de Walter Benjamin, enfatizando-se, aí, as suas ideias sobre a História.

\section{Sobre A Corte do Norte}

Oromance $A$ Corte do Norte se inicia com a história de Rosalina de Sousa, esposa de Gaspar de Barros, que, ao sair do Funchal, na Ilha da Madeira, para passar uma temparada na Corte do Norte, acaba por desaparecer sem deixar nenhum vestígio. Embora a versão oficial dos fatos fosse a de que Rosalina caíra das falésias e morrera, esta versão nunca foi confirmada, o que fez com que se aguçasse a curiosidade de representantes das cinco gerações que lhe seguiram, tendo esses descendentes promovido uma busca incessante pelo passado de sua família. Já na página 31, ao fim do primeiro capítulo, é narrado o fim da protagonista, que havia morrido "de desastre, despenhando-se das falésias do mar". Tratase, todavia, apenas do começo de um enigma: "A história parece 
terminar aqui, uma vez que propusemos ser a história de Rosalina. Mas aqui começa apenas o enigma e os seus ornamentos". ${ }^{1}$

A cada geração, novas versões sobre o destino de Rosalina foram sendo construídas, nenhuma delas completamente refutada ou aceita:

Mas Rosalina, praticamente sujeita à interpretação de três gerações, qual fora o seu trajecto? Morta por acidente, enquanto colhia ovos de pombos do mar, ou vítima de cólera e enterrada em segredo na capela dos Sanha? Ou então fugida na comitiva da Imperatriz [Elisabeth de Áustria] e seguindo-a fielmente nas suas excursões, envelhecendo juntas ao longo duma história dum vedetismo errante? (...) Era absurdo, mas o absurdo é uma perspectiva ao serviço da sedução; ele realiza a plenitude da sedução. Entre ela e a actriz Emília de Sousa, que pacto havia? Eram a mesma pessoa, e muita gente sabia disso e fingira liquidar o assunto com uma espécie de cumplicidade tutelar, mentindo, deixando a mentira enraizar-se como um roble, um dragoeiro imenso. Rosalina teria sido a actriz Emília de Sousa, a mulher mais querida e mais detestada de seu tempo (...). ${ }^{2}$

A impossibilidade de uma revelação definitiva que finalmente resolvesse o enigma se dá não só pelas várias versões criadas pelos descendentes da Baronesa, mas também, e principalmente, pela incerteza que perpassa toda a construção da narrativa. Nela, praticamente não há afirmações irrefutáveis. A narrativa se constrói por um "disse-me-disse", pelo que se dizia, pelo que estava na boca de uns, mas também o que estava na boca de outros. Muitas das afirmações encontradas no romance são posteriormente negadas, modificadas ou postas em dúvida a partir de questionamentos diretos e de construções

\footnotetext{
${ }^{1}$ BESSA-LUÍS, 2008, p. 31. Grifos meus.

${ }^{2}$ BESSA-LUÍS, 2008, p. 142.
} 
como o futuro do pretérito ("teria feito", "teria dito") ou do uso da expressão "dizia-se", sendo constantemente colocados em questão os "fatos" apresentados ao longo da história.

Isso pode ser observado no trecho citado anteriormente bem como em diversos outros pontos do texto. Já na página 14, na primeira menção feita à Baronesa, afirma-se que "Rosalina de Sousa, no dizer de seus contemporâneos, nasceu no Funchal em casa de modesto estadão mas abastada, que tinha uma cerca de bananal e um feixe de buganvílias vermelhas sobre a calçada". ${ }^{3}$ Aqui, novamente, a incerteza se coloca. Rosalina não nasceu no Funchal; dizia-se que ela nasceu no Funchal, assim como também se dizia que ela havia nascido em Porto Santo e, antes de se casar, trabalhava como prostituta. Da mesma forma como se deu a construção de várias versões sobre o destino de Rosalina ao longo da obra, muitas versões a respeito de sua origem vão sendo construídas, uma sempre colocando em xeque a versão dada anteriormente.

Não há, na obra, um narrador onisciente e não há nem mesmo uma coerência na narração, já que nela estão consideradas muitas versões para um mesmo fato, marcas de incerteza e informações contraditórias. Se Rosamund, bisneta de Rosalina, em um momento, era a filha preferida de seu pai, João de Barros, em outro, este nem mesmo gostava dela.

A obra é construída por variadas histórias, num sem número de possibilidades que se confirmam e se contradizem, não havendo uma só verdade: "E vi muitas lendas e muitas verdades; e, com estas, lendas e adivinhações. De tudo fiz este livro". ${ }^{4}$ Como argumenta Eduardo Lourenço, a escrita de Agustina Bessa-Luís

${ }^{3}$ BESSA-LUÍS, 2008, p. 14. Grifos meus.

${ }^{4}$ BESSA-LUÍS, 2008, p. 259. 
é caso para evocar a sempre jovem aventura de Penélope. Bessa-Luís vai tecendo com uma mão o que destece com a outra. Nada parece guiá-la, na aparência, senão uma fidelidade sonâmbula à vontade de desfiar por sua própria conta um fantástico rosário de 'relações humanas', tornadas em suas mãos como elementos de um 'puzzle' variável ao infinito. ${ }^{5}$

Nesse romance "teórico", não há desenlace. Nada se resolve, nada se fecha, sendo a verdade algo inatingível. São muitas as verdades, e ninguém, nem mesmo o narrador, as detém:

A quem me perguntar se de facto Emília de Sousa teve a vida dupla de Rosalina, Baronesa de Madalena do Mar, eu vou responder à maneira de Garrett quando, depois da estreia do Auto de Gil Vicente, quiseram saber se Bernardim se atirara ao mar e realmente se afogara, ao ver a nau que levava a princesa para sempre dos seus olhos:

- Isso não é comigo. Pergunte ali ao contra-regra, que ele é que está em condições de lhe responder. ${ }^{6}$

\section{A Corte do Norte e o pensamento de Walter Benjamin}

Como afirmado na introdução deste trabalho, neste romance, Agustina estabelece um diálogo, implícito e explícito, com diversos pensadores modernos. O pensamento benjaminiano, entretanto, pareceu sobressair-se, pelo menos quando se leva em consideração a construção do romance e seu principal assunto: o enigma do desaparecimento da Baronesa de Madalena do Mar.

${ }^{5}$ LOURENÇO, 1964 apud PEREIRA, 2006, p. 310-311.

${ }^{6}$ BESSA-LUÍS, 2008, p. 259. 
A visão de Walter Benjamin a respeito da história tradicional, cristalizada no século XIX, é bastante crítica. Para ele, a modernidade não mais possibilita esse fazer histórico, que é baseado numa ideia de experiência comum já não mais cabível no mundo moderno. Na modernidade, a experiência comum (Erfahrung), com a qual se identificaria todo um povo, perde espaço, dando lugar à Erlebnis, a experiência vivida. Isso significa que, na modernidade, as experiências pessoais, menores, passam a se sobressair em detrimento de uma já impossível experiência geral. Se a Erfahrung fracassa, fracassam com ela as formas de narração tradicionais, não podendo haver mais uma história totalizante, que dê conta de toda uma sociedade. Entra em cena o fragmentário, a incompletude, a impossibilidade de se contar, em apenas uma narração, a história de milhões.

O tempo, para Benjamin, diferentemente das concepções tradicionais, não pode ser homogêneo e vazio; trata-se, ao contrário, de um tempo "saturado de 'agoras'", 7 de um tempo em que um sem número de possíveis histórias convergem num movimento de aproximação e distanciamento. $\mathrm{O}$ trabalho do historiador "materialista" benjaminiano, é, portanto, o de se abrir para essas outras histórias e distanciar-se da ideia de que produzir um discurso histórico significa concatenar eventos que, numa ordem cronológica, culminariam necessariamente na configuração social observada no presente. Esse historiador deve abrir-se para novos fatos, para novas intervenções, "ao fazer junto", 8 e para a ideia de que a configuração social de um determinado momento não estava pautada em acontecimentos passados, não era a única consequência possível dos acontecimentos anteriores. Nessa perspectiva, o discurso histórico não deve e não pode explicar de forma definitiva o

7 BENJAMIN, 1994, p. 229.

${ }^{8}$ GAGNEBIN, 1994, p. 11. 
mundo presente; ele deve, assim como o exemplo de Heródoto, estar aberto a novas interpretações, a novas contribuições, a novos caminhos que não se podiam enxergar a princípio, num movimento de contínua adição e subtração de leituras.

Se não há experiência coletiva, a contribuição do máximo possível de experiências vividas passa a ser o único caminho para que se chegue a um discurso histórico minimamente capaz de "constituir uma experiência (Erfahrung) com o passado". É por esta razão que o historiador benjaminiano é comparado a um colecionador, a um construtor de um discurso caracterizado não por uma continuidade, mas por uma fragmentação, tratando-se não de algo como uma linha do tempo, e sim de um mosaico, de uma colagem, de uma mônada cuja principal característica é o não acabamento, o inconcluso.

Oromance de Agustina, ao apresentar inúmeras versões para o desaparecimento de Rosalina, funciona então como essa mônada benjaminiana, que abarca várias possibilidades, várias interpretações para um fato. Oromance é uma colagem, um mosaico de interpretações de um mesmo acontecimento, não sendo necessariamente um considerado mais verdade que o outro. A história de Rosalina é contada por todos. São várias gerações e vários os que "diziam" algo sobre ela, contribuindo para sua "construção". Sua história se abre para "o fazer junto" de que fala Jeanne-Marie Gagnebin ao analisar Benjamin, sendo construída a partir das várias experiências pessoais dos personagens:

O que era enigmático em Boal, para seu filho Francisco (...) não era a mesma coisa para Águeda, uma geração depois. (...) Mas passados mais de trinta anos, quando João, filho de Alice e de Tristão, chegou à Corte do Norte (...) podia derrubar a perspectiva de Boal que as outras gerações tinham produzido, só com animá-la com a sua linguagem. ${ }^{9}$

${ }_{9}^{9}$ BESSA-LUÍS, 2008, p. 138-139. Grifo meu. 
Este trecho leva a um outro ponto de convergência entre o texto de Agustina e o pensamento de Walter Benjamin: a ideia da construção da memória como uma questão de linguagem. A possibilidade de João de Barros derrubar tudo o que antes havia sido pensado sobre a memória de sua avó por meio da linguagem deixa clara sua força na construção da memória. Ao mencionar o jovem Benjamin de Origem do drama barroco alemão, Gagnebin toca na relação estabelecida pelo pensador entre filosofia, história e linguagem:

(...) com efeito, para Benjamin, a historicidade do pensar provém muito mais da historicidade da linguagem historicidade dos conceitos, dos usos linguísticos, das metáforas em vigor - do que de um índice temporal específico das questões tratadas. ${ }^{10}$

Um pouco mais à frente, a autora afirma ainda que o filósofo aponta para a "exigência de refletir sobre a 'essência linguística' do conhecimento". ${ }^{11}$ Sendo pensamento e linguagem indissociáveis, uma mudança na linguagem pode acarretar uma mudança no pensamento, ou na memória, como sugere o trecho do livro de Agustina há pouco mencionado. Transformado em linguagem, o conhecimento dos descendentes de Rosalina sobre seu fim passa a pertencer a todos e, por isso, torna-se passível de modificações, já que, neste momento, acontece uma "desistência de soberania, por parte do sujeito, em favor do objeto". ${ }^{12}$

Assim, nota-se um diálogo entre o pensamento benjaminiano e o romance aqui trabalhado. É possível que se questione, entretanto, até que ponto esse diálogo é intencional. Como já

${ }^{10}$ GAGNEBIN, 2001, p. 355.
${ }^{11}$ GAGNEBIN, 2001, p. 355
${ }^{12}$ GAGNEBIN, 2001, p. 361. 
afirmado, juntamente com outros pensadores modernos, o nome de Walter Benjamin é explicitamente citado na obra, exatamente no momento em que João de Barros, neto de Rosalina, se dá conta do fato de que é possível que haja várias verdades para um mesmo fato. $\mathrm{O}$ personagem, aspirante a historiador, "lia infatigavelmente obras que, no seu entender, lhe podiam fornecer pistas" de como desvendar o enigma da avó, e "uma das que mais o impressionaram foi um livro de Walter Benjamin que passou a trazer com ele, ainda que o esquecesse em qualquer lugar muito frequentemente" ${ }^{\prime 13}$

A partir da leitura desse trecho, pode-se notar que a relação entre a escrita de Agustina e a proposta de discurso da História apresentada por Benjamin não é algo casual. A passagem permite que se note uma ligação intencional entre as ideias benjaminianas e a construção do romance, já que foi João de Barros, leitor de Walter Benjamin, que chegou à conclusão de que "um fato é tão mais fato quanto mais se pode variar a sua composição; assim como uma lei é tanto mais lei quanto mais se pode transgredir". ${ }^{14}$ Embora se esquecesse do livro em qualquer lugar muito frequentemente (sua obsessão por desvendar o enigma não cessou de existir), o neto foi o primeiro a perceber, com a ajuda de Benjamin, que a história de Boal (apelido de Rosalina) se fortalecia com as diversas contribuições de seus investigadores, que, a cada nova possibilidade, faziam com que a figura da avó ganhasse mais vida.

Ainda que haja apenas uma (muito relevante) menção direta ao nome de Walter Benjamin no romance, a relação entre um e outro está longe de ser pontual. Como já afirmado, toda a construção do romance pode ser relacionada à concepção de discurso histórico e à ideia de memória como algo subordinado

13 GAGNEBIN, 2001, p. 194.

${ }^{14}$ BESSA-LUÍS, 2008, p. 129. 
à linguagem, desenvolvidas pelo pensador. Pode-se afirmar, também, que cada um dos personagens que se interessam pelo enigma de Boal é como uma espécie de historiador benjaminiano, que, por meio do contato com ruínas, com rastros de um passado em grande medida desconhecido, reconstrói a história inconclusiva de sua família e, por consequência, de si mesmo. Ao definir a tarefa desse historiador benjaminiano, Márcio Seligmann-Silva faz a seguinte afirmação:

O historiador/alegorista benjaminiano é aquele que se dirige para as ruínas da história/catástrofe para recolher os seus cacos. Diante dessa visão da História, não há mais lugar para a Historiografia tradicional - representacionista - que pressupunha tanto uma "distância" entre o historiador e o seu "objeto" como também a figura correlata do historiador como alguém presente a si mesmo e que segurava com firmeza e competência as rédeas do seu saber. ${ }^{15}$

Na busca por desvendar e reconstruir sua história familiar, cada um dos personagens busca recolher e agrupar seus cacos. Esses personagens não são historiadores no sentido estrito do termo, não chegam nem perto de alcançar o tradicionalmente desejável distanciamento de seu objeto e não conseguem segurar com firmeza as rédeas de seu saber. Na verdade, este saber aparece difuso, misturado a sentimentos de curiosidade, identificação e afeto, já que os historiadores de $A$ Corte do Norte o são não por escolha, mas pela necessidade de uma busca incessante pelo autoconhecimento e pelo fascínio que sentem pela enigmática antepassada. A construção difusa do saber, facilmente notável no romance de Agustina, está proposta por Benjamin, como se pode notar no seguinte trecho de Seligmann-Silva:

${ }^{15}$ SELIGMANN-SILVA, 2001, p. 369. 
(...) ao invés da linearidade limpa do percurso ascendente da história (do "Ocidente", do "Geist") tal como era descrita na historiografia tradicional, encontramos um palimpsesto aberto a infinitas re-leituras e re-escrituras. Tentemos agora nos aproximar mais desse modelo benjaminiano da temporalidade e do seu necessário e impossível registro. ${ }^{16}$

Ainda que estivesse tratando da teoria benjaminiana e de sua relação com a literatura de testemunho, o trecho citado poderia, facilmente, estar tratando de $A$ Corte do Norte. Sem a objetividade e a linearidade da história tradicional, o discurso histórico-literário construído no romance é também, de certa forma, impossível, uma vez que não se pode chegar a uma solução, a um único desenlace, a uma única resposta para o enigma de Boal.

\section{Considerações finais}

Este texto propôs uma discussão acerca do pensamento de Agustina Bessa-Luís e de seu diálogo com o pensamento moderno, mais especificamente com a proposta de discurso histórico alternativo elaborada por Walter Benjamin. Em $A$ Corte do Norte, é notável o diálogo com esse pensador não só em seu conteúdo, mas também, e principalmente, na forma como foi construído o romance, sendo possível que se pense até mesmo que se trata ali de uma tentativa de se pôr em prática por meio da literatura essa proposta de discurso histórico, em especial a mônada benjaminiana.

Com seu romance inconcluso, aberto para interpretações, cujo enredo é na verdade um "antienredo", já que nada é certeza e tudo o que é narrado é posto em dúvida pela própria

${ }^{16}$ SELIGMANN-SILVA, 2001, p. 365-366. Grifo meu. 
narração, Agustina Bessa-Luís construiu uma forma bastante original de se escrever ficção, produzindo uma obra literária que presta uma espécie de homenagem ao pensamento moderno.

\section{Referências bibliográficas}

BENJAMIN, Walter. Sobre o conceito da História. In: . Magia e técnica, arte e política. 7. ed. São Paulo: Brasiliense, 1994. (Obras escolhidas, v. 1).

BENJAMIN, Walter. Origem do drama barroco alemão. Tradução, apresentação e notas de Sérgio Paulo Rouanet. São Paulo: Brasiliense, 1984.

BESSA-LUÍS, Agustina. A Corte do Norte. Lisboa: Guimarães Editores, 2008.

GAGNEBIN, Jeanne-Marie. Mímesis e crítica da representação em Walter Benjamin. In: DUARTE, Rodrigo; FIGUEIREDO, Virginia (Org.). Mimesis e expressão. Belo Horizonte: Editora UFMG, 2001.

GAGNEBIN, Jeanne-Marie. Walter Benjamin ou a história aberta. In: BENJAMIN, Walter. Magia e técnica, arte e política. 7. Ed. São Paulo: Brasiliense, 1994. (Obras escolhidas, v. 1).

LOURENÇO, Eduardo. Des-concertante Agustina: a propósito de Os Quatro Rios. O Tempo e o Modo, n. 22, [s.l.], [s.n.], 1964.

PEREIRA, Elsa. A Corte do Norte, de Agustina Bessa-Luís, ou o romance da saudade. Revista da Faculdade de Letras - Linguas e Literaturas, Porto, vol. XXIII, II série, 2006 [2008], p. 307-324.

SELIGMANN-SILVA, Márcio. A catástrofe do cotidiano, a apocalíptica e a redentora: sobre Walter Benjamin e a escritura da memória. In: DUARTE, Rodrigo; FIGUEIREDO, Virginia (Org.). Mimesis e expressão. Belo Horizonte: Editora UFMG, 2001. 


\section{Resumo}

A escrita de Agustina Bessa-Luís tem um forte tom filosófico. Por meio de sua ficção, a escritora, conhecida por seus aforismos e digressões, foi capaz de construir um pensamento próprio, que dialoga, implícita e explicitamente, com grandes nomes do pensamento moderno. Neste artigo, privilegiar-se-á a relação estabelecida pela autora com o pensamento de Walter Benjamin, mais especificamente suas ideias sobre o discurso histórico, no romance $A$ Corte do Norte, visto que, nesta obra, o tom filosófico da escrita de Agustina fica ainda mais evidente, e a questão do discurso histórico é de suma importância para a construção da narração.

\section{Abstract}

Agustina Bessa-Luís' writing has a strong philosophical take. The writer, famous for her aphorisms and digressions, was capable of building her own, and quite unique, way of thinking, which dialogs, implicitly and explicitly, with great names of Modern Thought. The aim of this essay is to privilege the relation established by Agustina with Walter Benjamin's propositions on an alternative way of studying and discussing History in her novel $A$ Corte do Norte, in which the author's philosophical take on literature becomes even more evident, and the matter of History is crucial for the way narration is constructed. 